\title{
The Core Concepts of Disability Policy Affecting Families Who Have Children with Disabilities
}

\author{
H. Rutherford Turnbull III, Gwen Beegle, and Matthew J. Stowe
}

\begin{abstract}
This article reports the research that resulted in the authors' identifying 18 core concepts of policy affecting families who have children with disabilities. It sets out the research methodology; defines the 18 core concepts; distinguishes between policy that affects primarily individuals with disabilities on the one hand and policy that affects the families of children with disabilities on the other hand; and deliberately does not discuss generic "family policy," even though families affected by disability are also influenced by that body of policy.
\end{abstract}

In this article, we describe our research process, the resulting 18 core concepts of disability policy affecting families who have a child with a disability, and our approach to them, which is to describe but not try to reconcile them when they conflict with each other. We also refer to a matrix of legal source material that serves as a reference guide for all the articles in this series.

\section{A Three-Part Research Process}

To identify the core concepts, we used three research methods simultaneously: a literature review that included an analysis of relevant law (statutes and cases) and legal commentary, a participatory action research (PAR) process, and a qualitative data analysis. What follows is a description of these methods and how they were used.

Our review of disability policy literature, relevant statutes, and case law yielded an initial matrix (April 1999) in which we preliminarily documented the core concepts. Our PAR committee (consisting of consumers, policymakers, and researchers) gave initial and formative comments during this review process. We then revised the matrix and identified and defined the 18 core concepts. For each core concept, the matrix (a) defines the core concept, (b) identifies the principles or provisions of the federal Constitution on which the concept is based, (c) identifies and cites to the provisions of the federal statutes that exemplify the concept, (d) lists the federal case law related to the statutes, and (e) identifies other case law relevant to the core concept. Throughout our research, we have continued to update and revise the matrix so that it now reflects the relevant decisions of the United States Supreme
Court and the Acts of the 106th Congress (through December 2000). The most recent matrix (May 2001) follows this article and is a reference source for the other articles in this series.

After developing the initial matrix in April of 1999, we conducted interviews and focus groups with disability policy experts, asking them to confirm, modify, explain, exemplify, or reject the core concepts as set out in the matrix. We used purposive sampling to ensure that the research respondents were widely recognized as knowledgeable in the field and had policy development, advocacy, and service delivery perspectives. To secure varied expertise and perspectives, we spoke with persons involved in making policy in Congress and the state legislatures; implementing it in the federal, state, and local executive branches; and benefiting from it as families who have children with disabilities. Accordingly, the respondents represented both federal and state perspectives across two branches of government and consumers.

Twenty-four individuals with family, legislative, administrative, or professional expertise representing the federal perspective participated in a focus group or were interviewed individually. In addition, 20 disability policy researchers participated in focus groups and were interviewed individually. Forty-seven individuals from two states (Kansas and North Carolina) representing a state-local perspective participated in eight focus groups and 10 individual interviews. The types of state participants mirrored the federal respondent groups: family members, state legislators, administrators, and professionals. Finally, 17 health policy expert respondents participated in three focus groups and one individual interview. In all, 108 individuals participated as research respondents.

Following each of the focus groups and interviews, we mailed to each respondent a transcript of the respondent's 
statements or (if we did not record and transcribe the respondent's remarks) our notes of the respondent's remarks. We asked the respondents to confirm, modify, or delete any statements that did not accurately reflect their comments. We advised each respondent that we would assume that our records were accurate unless the respondent advised us otherwise. No substantive corrections were required.

In addition, during the focus groups and interviews, we asked the respondents to confirm, modify, or delete any text within the initial matrix that did not accurately define, describe, and exemplify the core concepts listed there. A few respondents added references to statutes and cases, but most accepted the matrix as an accurate and comprehensive reflection of the core concepts.

In concert with our Participatory Action Research committee, and with the assistance of eight doctoral students in special education who read and analyzed the transcripts, we used the resulting field notes, transcripts, and analyses to refine the core concepts into those set out in the final matrix. The 18 core concepts thus are the product of literature review, document analysis, and qualitative research methods.

\section{Two Preliminary Questions and Their Resolution}

As we began to identify and define the core concepts, one key issue became apparent: Who is the primary beneficiary of the policy that we were researching-the child with a disability or the child's family? And, would the answer to this question make any difference in defining core concepts?

Notably, commentators who have recently written about core concepts did not separate the policies in terms of primary and secondary beneficiaries (Braddock, 1987; Silverstein, 2000; H. R. Turnbull \& Barber, 1985). Nor did our respondents suggest that we do so. Yet, it could be argued that some of the core concepts are more relevant to individuals who have disabilities than to their families. For example, antidiscrimination may be more important to the person than to the person's family, whereas family centeredness may be equally important to the family and the person. Does the primary/secondary beneficiary distinction make a significant difference in how we understand the core concepts? We think not: Policy that affects a person with a disability (including a child) also affects the person's family so long as the person and family are involved with each other in the sense of performing any family functions together. These functions relate to affection, self-esteem, economics, daily care, socialization, recreation, and education (Turnbull \& Turnbull, 1997).

Even though it seems that the primary/secondary beneficiary question does not make a significant difference in how we understand the core concepts, we nonetheless have limited our core concepts to those that affect families who have children with disabilities. The fact that many of our core concepts also have been identified as core concepts affecting disability policy generally (Silverstein, 2000) seems to us to simply reinforce what we assert: namely, that we have indeed correctly identified the core concepts of disability policy affecting families who have children with disabilities. Moreover, the fact that our results are based on three different research methods and take into account the relevant case law (which most other analyses do not) also suggests the validity of our results.

A second issue that arose was the interaction of two pol icy arenas: disability policy on the one hand and family policy on the other. The work of other researchers in the field of disability policy-and, indeed, our own research-generally reflects the narrow but defensible perspective of considering disability policy primarily as it affects individuals with disabilities and their families. With only a few exceptions (see, e.g., Minow, 1990), many disability policy researchers disregard the overall effect of family policy in general on individuals with disabilities and their families. Yet, disability policy, especially as it affects families who have children with disabilities, clearly is nested within the larger policy arena. Disability policy is affected by, and in turn affects, the larger family policy landscape. Thus, we occasionally refer to some examples of generic family policy in our matrix and in the other articles.

\section{Identifying, Defining, and \\ Explaining the Core Concepts and Addressing the Conflicts Among Them}

\section{Identifying the Core Concepts}

Reflecting the research process we just described, we now (a) identify each of the 18 core concepts by name, (b) state the most obvious issue or issues related to it (as a way of focusing the readers' attention on why the concept is "core"), (c) explain the nature of the claim that people with disabilities and their families make (also as a way of focusing the readers' attention on why the concept is "core"), and (d) briefly describe the relationship of the concept to other core concepts and to various legal and other principles that have guided disability policy.

\section{Defining the Core Concepts}

As we describe each core concept, we use the language that our PAR team members and research respondents used or the terms that appear in the relevant statutes and case law. As we state the most obvious issue or issues related to it, we refer to a well-known history but do not document it, as that has been done quite well by others (Blatt, 1970; Blatt \& Kaplan,1974; Blatt, McNally, \& Ozolins, 1978; Bowe, 1978; Brakel, Parry, \& Weiner, 1985; Ferguson, 1990; Goffman, 1963; Gould, 1996; Groce, 1985; Kindred, Cohen, Penrod, \& Schaffer, 1976; Levy \& Rubenstein, 1996; Minow, 1990; Sales, Powell, 
VanDuizend, \& Associates, 1982; Scheerenberger, 1983; Shapiro, 1993; Smith, 1985; Stiker, 1997; Trent, 1994; Wolfensberger, 1975).

\section{Explaining the Core Concepts and Their Listing Order}

The organization of the core concepts (for example, antidis crimination first, followed by individualized and appropriate services) is consistent with the matrix and is ours alone, as are the statements of the issues or claims and the transition sentences. We do not insist that our ordering is perfect; others may list the concepts differently (and indeed Silverstein [2000] did), but our ordering has a logic to it.

We begin with antidiscrimination because it has been the focus of a substantial amount of dis ability policy and indeed was one of the original foundations upon which progressive policy has been based. We then address three core concepts? individualized and appropriate services, classification, and capacity-based services?that have to do with the same issues: who gets what, why, and under what kind of eligibility-determination standards and processes. The next core concept? empowerment/participatory decisionmaking? involves the role of the consumer (family) in affecting what services are received and how they are delivered. Such participation must be made effective and meaningful through the core concept of service coordination and collaboration carried out among families and professionals.

Next, we set out the core concepts most connected to the capacity and freedom to participate and collaborate. The core concepts of protection from harm and liberty relate to freedom from confinement and the conditions of confinement. Autonomy then follows, as it involves freedom from governmental or other outside interference in personal decision-making. Consent requires access to necessary information, so the focus of the next core concept? privacy and confidentiality? is control of information.

The next set of core concepts turns the discussion to positive rights: "freedoms to" rather than "freedoms from." Integration and productivity and contribution are both outcomes of the preceding core concepts; they are what can be obtained if people do not experience discrimination and if they are provided with effective services. As effective services require consideration of disability as it affects the whole family, the core concepts of family integrity and unity, family centeredness, and cultural responsiveness involve the well-being of the family.

But effective service provision also relies on the core concept of accountability to ensure that what those concepts promise indeed is what the families receive. The core concept of professional and system capacity-building directs improvement in the delivery of the other core concepts and fidelity to the goals of the core concept of prevention and amelioration: to prevent or ameliorate the effects of disability.

\section{Addressing Conflicts Among Core Concepts in the Context of Families and Children}

It is indisputable that some core concepts will conflict with others. For example, conflicts exist between a family and its child with a disability. These are the intrafamily conflicts where the parents have certain claims based on some core concepts and the child has certain claims based on opposing core concepts. For example, a family's interest in its autonomy, privacy, and cultural traditions may well imperil the child who has a disability; here, the conflict is between the interests of the adult family members (ostensibly the parents) and the child's interest in being protected from harm, from being denied liberty through institutionalization, or in being denied the opportunity to participate in decisions affecting autonomy. Classic examples of these kinds of conflicts arise when involuntary sterilization, institutional placement, withheld medical treatment, imposition of certain interventions, or transition to adulthood is the issue at hand.

Other types of conflicts also exist. For example, a person with a disability may well assert a claim to autonomy and liberty?to decision-making power and to freedom from confinement?but be challenged by other individuals' claims to be free from the person's dangerous or otherwise unacceptable or inappropriate behavior. For example, conflict occurs between, on the one hand, policies advancing the "zero reject" principle of the Individuals with Disabilities Education Act (IDEA) and its provisions related to discipline and, on the other hand, policies advancing school safety. It also arises when a person's interest in privacy and confidentiality conflicts with other persons' desires to be protected from harm. In this case, the person's privacy and confidentiality rights are subsumed to a third party's interest in protection from harm. Conflict also arises when a family decision maker (usually a parent) wants to withhold or withdraw efficacious medical treatment from a child or adult member with a disability who is at the end/edge of life and for whom a sanctity-of-life claim may be asserted in opposition to a family claim to autonomy and a personal claim to quality of life. Many other examples exist.

Should we in our research capacities attempt to resolve the conflicts or, at a bare minimum, to give guidance on how to resolve them? (Notice the qualifying clause "in our research capacities.") This question arose while we were conducting our research. Some of our respondents argued that we should attempt to resolve the conflicts, or that at the least we should say how we would approach their resolution. They thus were linking the researcher role to an advocacy role. On the other hand, other respondents acknowledged that as researchers we have a much more limited role-namely, to set out what the respondents, statutes, and cases say but not to resolve the conflicts. They regarded the research role as separate from a decision-making or advocacy role, and they also argued that abstract resolution is unlikely to be satisfactory: Facts drive results and resolution. That is, they said that contextually 
driven resolution is preferable to abstract resolution. Still other respondents argued that no single core concept is so compelling that it will trump all other core concepts; relativity, not absolutism, governs.

In our present role as researchers whose immediate obligations are to report on the core concepts and then to organize them and suggest how they can be practical and useful, we have taken a "disinterested" posture and do not offer our ideas on which core concepts should prevail over other core concepts, either in the abstract or in contexts where facts inform the results. Candidly, that is not an altogether comfortable conclusion, for at least one of us (Turnbull) has a long record of advocacy on behalf of people with disabilities and their families and has argued that "knowledge is power only if the knowledgeable act powerfully" (A. P. Turnbull et al., 2000). The other authors of this special series have taken their own but less nationally notorious positions as advocates. We concede that context (a research report) and role (research, not advocacy) control behavior. That is a conscious choice. It is now appropriate to describe, explain, and contextualize the core concepts. (In the articles later in this issue on models and tools we describe how the concepts can be used?contextualized in a practical way?by policy analysts.)

\section{The Core Concepts}

\section{Antidiscrimination}

The core issue is discrimination based on disability. This core concept holds that discrimination on the basis of disability alone violates an individual's rights to equal protection under the federal Constitution and to equal treatment and equal opportunity.

These latter two terms can cause confusion, so it is worthwhile to define them in the ways that the disability community and the lay public may define them. Equal treatment arguably includes exactly equal treatment: A person without a disability and a person with a disability are treated exactly alike. Of course, that may discriminate by producing unequal opportunity; alternatively, it may not. Why? Because in some contexts, some disabilities do not impair or impede a person's participation; for example, a student in a wheelchair can learn Latin as easily as one who walks, assuming both have somewhat the same cognitive capacities. In other contexts, however, exactly equal treatment will result in discrimination: A deaf student who is not provided an interpreter or other accommodations certainly will not benefit from the same Latin class as a hearing student who has comparable cognitive abilities. In the first scenario, exactly equal treatment produces equal opportunity. In the second, exactly equal treatment produces discrimination (denial to benefit because of disability), but equal treatment plus an accommodation?that is, admission to the Latin class with an interpreter or other appropriate accommodation?produces equal opportunity to benefit.
Finally, some people have such extensive disabilities that they will not experience equal opportunity to benefit unless they are treated quite differently from those who have no disabilities or have less challenging disabilities. For example, a person who uses a wheelchair, a "joy stick" to operate a computer, and augmentative communication will not be able to hold down a desk job unless provided with an ergonomically suitable desk, a computer that responds to the commands of a joy stick (instead of a mouse), and allowances to "speak" face to face or on the telephone by using the augmentative commu nication device. In this case, unequal but noninvidious treatment produces equal opportunities to work.

These three "tiers" of equality?exactly equal treatment, equal treatment plus accommodations, and unequal but noninvidious accommodation (National Council on Handicapped, 1986; H. R. Turnbull, Turnbull, Stowe, \& Wilcox, 2000; U.S. Commission on Civil Rights, 1983)?are manifestations of disability-specific approaches to equality. The distinctions between each of these tiers and how they are operationalized are important to policymakers (and their constituents) who want (or do not want) to attack discrimination in an effort to offer people with disabilities the opportunities to participate in the "nondisabled world:' Unless policymakers, their constituents, disability advocates, and those who oppose "special (i.e., unequal) treatment" understand the distinction, discrimination will be the bill of fare on the table of many people with dis abilities and their families.

Thus, to some of our respondents, the claim of a person with a disability to civil rights is at one time a claim to be treated the "same" as "similarly situated" people. The claim is to equal opportunity for full participation. As the executive director of a national disability advocacy organization put it, his organization's goal is to "increase the participation of persons with disabilities till those persons are satisfied that they have the same degree of participation as nondisabled citizens.... Only then will America have fulfilled its promise for people with disabilities."

One purpose of antidiscrimination is to ensure that decisions about an individual are made objectively and on the basis of the whole person, including the person's capabilities, impairments, and preferences. A more fundamental purpose (more fundamental because it is linked to the constitutional doctrine of equal protection) is to promote equal opportunity to participate and benefit. For example, the claim of students with disabilities to a free and appropriate public education is a claim to be treated as students and thus to have access to education, just as nondisabled students have a right to go to school. The same logic applies to the claim to participate in federally assisted programs or in the public and private sectors; however, in both cases some accommodations? indeed, even very extensive ones?must be made in some contexts for some students. Accordingly, civil rights laws provide that an individual with a disability (a) may not be subjected to discrimination solely on the basis of 
disability, (b) is entitled to reasonable accommodations (not affirmative action) to qualify and participate, and (c) is thereby protected under the 14th Amendment's equal protection clause. An administrator of a large federal agency referred to this as "human investment," asserting that everyone, with or without a disability, has $a$ claim to beneficial services.

\section{Individualized and Appropriate Services}

The central issue evolving out of antidiscrimination is how to translate the claim to equal opportunity into a reality. The response is individualized and appropriate services.

Education, employment, health care, or other types of services that are (a) genuine ("real" service), (b) effective and efficacious (actually does for the person what the providers say the service will do), and (c) meaningful (that is, valuable to the beneficiary) must be based on a fair (nondiscriminatory) evaluation of the beneficiary (see below under the core concept of classification). It also must be based on the person's capacities, needs, and preferences and on the reasonable judgment of the professionals or other individuals offering the service. Individualized and appropriate services meet the standards of the profession of the person offering them. This core concept is illustrated when services are "seamless" from provider system to provider system (e.g., from early intervention to early childhood education, or from secondary education to adult activities) or from place to place and across jurisdictions (so that a person's zip code does not determine access to a service, much less an effective one). Finally (as we explain later), individualized and appropriate services incorporate the least drastic means of intervention, treatment, habilitation, rehabilitation, or other amelioration.

Accordingly, disability entitlement laws require services to be specially tailored to meet individualized needs in family and individual support, education, treatment, habilitation rehabilitation, and work. As a former federallevel Cabinet member put it, "Ultimately, individualization is the function of the ingenuity of the person, family, and community, and the product of the sensible use of funds and decisions of sensitive policymakers."

Principal methods for achieving individualized and appropriate services include "classification," "capacity-based services," "empowerment and participatory decisionmaking," and "service coordination and collaboration." Also, under antidiscrimination laws-and in order to secure individualized and appropriate services-reasonable accommodations or other modifications to services, policies, practices, and procedures are required unless they fundamentally alter the nature of the particular service or program or result in an undue hardship to a service or program. Physical and technological (communication) accessibility are aspects of individualized and appropriate services.

\section{Classification}

The core issue here is whether a person qualifies for the individualized and appropriate services described above based on the eligibility standards set forth by a service system. The claim is to a fair distribution of limited resources through qualification or prioritization based upon measurable criteria that are applied nondiscriminatorily to the individual. A related claim is to receive services that prevent a disability from occurring or that prevent an existing disability from causing further impairment. Part $\mathrm{C}$ of IDEA, which authorizes federal assistance for state and local services to infants and toddlers who have developmental delays or have physical or mental conditions that carry a high probability of causing developmental delays, is a good illustration of a prevention policy.

The term classification refers to the processes (ways) and the standards (criteria) by which a person with a disability or the person's family qualifies (becomes eligible) to benefit from certain laws (antidiscrimination or other rights or entitlements). The criteria for eligibility often relate to the severity of a person's impairment or the extent of a family's need; at times, these factors are considered together. As a Kansas state-level program administrator stated, "Severity of a person's disability is a factor [in providing developmental disability services].... Judgments are made?we don't have a calculus or a tool to measure it?but severity of disability is a factor, along with whether it becomes a crisis [for the person or family] if a waiting list is used."

In other examples of classification, a child qualifies for IDEA benefits when he or she cannot benefit from general education; a person receives Supplemental Security Income and Medicaid benefits when he or she "meets" certain severeneed, medically based criteria. This matter of selectivity is, of course, subject to the valid criticism that the person becomes "pathologized"?the person's need and deficits become the criteria for eligibility.

Frequently, these matters of classification and priority are related to resource allocations and rationing. "For the severe and neediest populations," said a Kansas state administrator, "you need a way to preserve the dollars to serve the neediest of those" Classification and priority also are remedies fashioned under antidiscrimination law enforcement and legislation. For instance, a Kansas state educator pointed out: "[W]e have Title I and special education emanating from the federal government because folks locally weren't taking care of those kids who needed those services." Thus, classification, despite its negative connotations, is frequently seen as a means by which difficult-to-serve subpopulations can be ensured of access to individualized and appropriate services.

\section{Capacity-Based Services}

How should a service be provided once a person is determined to be eligible for it? Although classification often is based on need and priority related to severity, services nevertheless should be focused not just on the person's needs but also on the person's capacities. The claim is to services that regard the person with a disability or the family wholistically, that is, to services that take into account the beneficiary's limitations and capacities. 
The term capacity-based services refers to (a) the evaluation of the unique strengths and needs of a person with a disability or the person's family and (b) a person- or familydirected evaluation of the resources, priorities, and concerns, and identification of the services necessary to enhance the capacities, of the person with the disability or the family. The claim is twofold: to remediate the person's deficits and simultaneously to build on the person's strengths. This dual approach seeks to reduce the "fix it" or "pathology-based" approach that has rendered individuals with disabilities and their families subservient to professionals; it seeks to overcome the power relationship that traditionally has favored the profes sional over the person or family.

Capacity-based services recognize that if improvement of the individual's or family's quality of life is the goal, rather than solely the amelioration of disability, then services must be person-centered and grow from the strengths of the individual, not just his or her disabilities. Accordingly, IDEA requires a multidisciplinary and comprehensive evaluation of the strengths and needs of the student. In early intervention, IDEA also requires a family-directed assessment of the resources, priorities, and concerns of the family in order to identify supports and services necessary to enhance the individual and family capacity to meet the needs of the infant or toddler.

\section{Empowerment/Participatory Decision-Making}

This core issue involves ensuring that the services are in fact delivered in a way that is individualized, appropriate, and capacity-based while simultaneously respecting the autonomy of the individual and family. According to the administrator of a large federal agency who also is $a$ parent of a young adult with a significant disability, "Disability is best defined as a role limitation that [affects] not only the person but also the person's family. People without disabilities cannot appreciate that role limitation, and they therefore have difficulty designing policies and operating programs for people with disabilities and for their families."

Accordingly, the claim is to shared responsibility and decision-making power between the provider/professional and the beneficiary/recipient. They should jointly decide, with appropriate deference to each other's expertise, preferences, and roles, what services and supports will be effective in achieving jointly agreed-upon outcomes; thus, planning, developing, delivering/implementing, and evaluating services are joint activities.

When this kind of participatory decision-making occurs, it sometimes causes another core concept to come into play: empowerment. Empowerment?getting what a person or family wants and doing so in the way that the person or family wants? is contextual: The circumstances, professionals, settings, and policies surrounding the person or family facilitate or impede empowerment (A. P. Turnbull \& Turnbull, 1986, 2001).
Empowerment is also dynamic: It affects a person or family differently at different times and in different circumstances. It is both a result of participatory decision-making and a principle that supports participatory decision-making.

Accordingly, many social programs create, or at least do not close off, various options for services and methods of service delivery while simultaneously granting opportunities to individuals, families, and professionals to contribute to the decision-making process. Their contributions are at both the macro/system-wide level and the micro/individual level.

\section{Service Coordination and Collaboration}

People with disabilities and their families often have needs that cut across various domains of their life, yet services too often are organized and delivered without regard to those transecting needs. Metaphorically, the issue is how to satisfy the horizontal needs of people and families through the use of traditionally vertical service-delivery sectors/strands. The claim is for a policy response to ensure that services are coordinated, that professionals collaborate with each other, and that funding streams are "braided" with each other (like a braided belt, each stream [strand] retains its own identity but is tightly associated with others to create a whole and therefore more useful flow of money).

As a state-level program administrator in North Carolina put it, "[We need to] mix the service-delivery funding streams; create flexibility; create a single, unified stream of health, mental health, developmental disabilities, and social services, administered locally." The typical techniques include various forms of partnerships between or among service delivery professionals and various forms of service delivery, commonly called school-linked, community-linked, unified, coordinated, intrasector/agency, intersector/agency, seamless service delivery, one-stop shopping, integrated or braided services, and funding streams. Accordingly, laws granting services to individuals and families increasingly require service providers to adopt methods that "harmonize" the various sectors of public assistance. Coordination and collaboration thus refer to activities that enable and assist persons and families to benefit from their rights and entitlements; they refer to making effective, across service-delivery sectors/strands of the individualized and appropriate services to which there is a claim. Coordination and collaboration will ultimately lead to "whole" systems that respond wholistically to individual needs, which one federal administrator referred to as "mass customization."

However, powerful policy, administrative/bureaucratic, organizational, financial, constituent, professional/ disciplinary, and training impediments block service coordination and collaboration. Administrators must substantially dismantle existing organizations in order to achieve greater coordination, as noted by a Kansas regional administrator of disability services: "One of our [state agency] initiatives is to break down our traditional 
stovepipes ... separate commissions on mental health, child welfare, any number of things. We want to move to a more integrated service delivery that keeps the family at the center."

\section{Protection From Harm}

How can the state ensure that the person and family experience no harm as a result of being recipients of services? Here the claim is "negative" in nature: It is a claim against certain kinds of behavior by others. This behavior can be by state or local government personnel, by personnel employed by private agencies, or by family members. Restrictions on aversive interventions and preferences/presumptions in favor of positive behavioral supports, restrictions on electroconvulsive shock therapy, and restrictions on the use of psychotropic medications or physical restraints and seclusion reflect the protection-from-harm concept.

A different issue is how to ensure that the person and family gain access to services and supports that ameliorate the harms they may be suffering in their current environments. Here, the claim is "positive" in nature; it "sounds" or is grounded in prevention (itself a core concept) and in the liberal, post-Enlightenment argument that the role of government-of the "welfare state"-is to provide affirmatively for its citizens. This claim is more than an extension of the doctrine of parens patriae (the state is the "parent" of those who cannot look after themselves); it is more than a claim to paternalism. It is instead a claim that the state should take an affirmative, positive role in enhancing the quality of life of its citizens.

Said one federal agency administrator who also is a parent of a young adult with significant disabilities, "The key is a basic level of safety, cleanliness, and health and a basic level of freedom." The core concept is protection from harm at the hands of others (state, local, or private agency personnel, or family members). Laws that (a) prohibit abuse, neglect, and maltreatment; (b) put into place procedures and standards for preventing, investigating, and prosecuting; and (c) construct systems for treating victims of abuse, neglect, and maltreatment exemplify this core concept. Underlying this core concept are the concepts of safety and security.

Related to it is the duty of providers to warn and protect third parties about the behavior of the person with a disability who is receiving services from them because that person may be dangerous to the third party or because it is necessary to ensure a safe school or other environments. There is a right of third parties to be protected, just as there is a right of persons with disabilities and their families to be protected.

Accordingly, this core concept is a driving force behind laws such as those governing adoption, foster care, and child welfare. It is also evident in disputes about the right to treatment, the right to the least restrictive environment and least drastic alternative intervention, the liability of a state regarding individuals within its custody, school discipline and safeschool laws, and a host of entitlements based on such factors as disability (or the extent of disability) and poverty.

\section{Liberty}

People with disabilities sometimes have been unjustifiably denied their liberty, that is, their physical freedom. The core concept is the right to liberty, to be free from unwarranted state confinement and intrusion. Of course, this core concept relates to another, namely, integration (the right to be included in the world that people without a disability take for granted). Because the interest in liberty is so powerful and distinguishable from the interest in integration, it deserves its own separate place as a core concept.

A state-level program administrator in Kansas reflected on the importance of liberty to his work:

When I got into the community-based deinstitutionalization business, I asked adults with mental retardation what they wanted to do with their lives, and I listened. They didn't want to be where they were, and they didn't want to be doing what they were doing. They were there because a court put them there. I thought, if you can be put away because of a particular label, then maybe brown-eyed people with hook noses like me will be next.

Liberty here has a "negative" connotation. As a researcher noted, it is a right to be protected against unjustified state action, to have a protective wall around the person and family.

States have denied individuals their freedom through civil commitment and through other forms of physical or chemical restraint. States have justified depriving individuals of their liberty on the basis of the state's police power (a state's right to protect others from dangerous people) and on the basis of the doctrine of parens patriae.

Whenever state action is justified, it is balanced against the individual's residual rights to liberty; the most common balancing principle is the doctrine of the least restrictive alternative/environment. That doctrine holds that whenever the state has a legitimate reason to act (to deprive a person of his or her liberty), it must act in the way that is least restrictive of the person's freedom. Accordingly, the place of restriction (for example, a prison or institution) and the method of restriction (for example, physical or chemical restraints) are equally important considerations in the issue of liberty.

People with disabilities thus have the right to expect that services will be offered to them in ways that are least restrictive of their liberty, with a preference toward generic and community-oriented services over specialized and institutional-based services. When a person is segregated in a treatment or educational facility or program, the person loses (a) access to and an opportunity to participate in community and (b) personal autonomy. Many of the researcher respondents noted that closely related to liberty are claims that the person or family is entitled to be treated with respect and dignity, particularly because some denials of liberty are accompanied by degradation and humiliation. 


\section{Autonomy}

The issue raised by the concept of autonomy is whether the person with a disability and the person's family may legally exercise control over the state's and professionals' actions. The claim is to make decisions about one's own life and to have those decisions honored by others.

Autonomy is the premise that individuals are and should be supported to be their "own" person. It supports the right of a person or family to say "yes" or "no"?and then to withdraw that "yes" (consent) or "no" (refusal to consent)?to what the state wants to do to, for, or with the person or family. In legal terms, autonomy is often expressed as consent. In service delivery, it is called choice, control, self-determination, selfdirection, self-responsibility, or person-directed services (also called "consumer-directed" or "client-directed" services). Note that autonomy is linked to another core concept, namely, empowerment/participatory decisionmaking. This is so because both reflect the value of individuals having power to affect what happens to them; however, these two core concepts differ from each other. Autonomy is more basic; it refers to the state of being selfgoverned, to self-directing freedom and the moral independence of a person or family. By contrast, the core concept of empowerment/participatory decision-making refers to the ways in which a person or family acts after the person or family consents/chooses to act. The consent/choicethe autonomous action-precedes the person's participation with others in various decision-making processes, and it terminates that participation, too. A person may consent/choose to participate or not and may withdraw from participating. That consent/choice is the autonomous action; the participation is its manifestation.

So central is autonomy to quality of life that one Kansas state-level administrator stated that "the outcome of your services?your quality of life? is living where you want to live, with whom you want to live, working where you want to work, with whom you want to work." The claim is to personal autonomy and is achieved through the legal right to give, refuse, or withdraw consent. If a person or family is incompetent to exercise the legal rights of consent, a duly appointed surrogate may do so.

Clearly, the core concept of autonomy is highly related to physical independence. The individual's ability to live and act on one's own, or with assistance as chosen by the individual ("independent living"), is a symbolic representation of the core concept of independence. The fact that it is a symbol does not make independent living and action any less important. Independence is necessarily advanced by supports provided to the person or family; human interdependence does not detract from the core concept's expression. Few people are truly independent actors. Indeed, interdependence acknowledges that we all are social beings and that for individuals with disabilities, independence can co-exist with interdependence if, especially if, the person has access to needed supports (tech nological, personal, and financial) and if the person controls these supports.

Independence also means that people have the right and capacities to determine who provides what kind of assistance and how, when, how long, where, under what circumstances, and for what purposes. As a Kansas state-level administrator stated, "To me, [choice] means that an individual and/or a family have preferences about what they want their life to be like and that those [preferences] are honored." Highly related to autonomy are the concepts of participatory decisionmaking/ empowerment, and privacy and confidentiality.

\section{Privacy and Confidentiality}

The issue covered by this core concept is whether and, if so, to what extent do individuals with disabilities and their families control the arguably public aspects of their lives. There are two claims ?privacy and confidentiality.

The first claim is to privacy, to a zone into which the state, professionals, and private entities may not enter without consent of the family or individual (see autonomy). This core concept extends the freedom from interference that is the bedrock of the core concept of autonomy to freedom from observation and oversight within a protected zone. The protection allows the individuals and their families to make certain decisions without state or professional oversight and without the possibility of a state or professional veto. Typically, these decisions are of a purely or predominately private nature and include, for example, whether or not to avail themselves of certain interventions or services.

The second claim is to confidentiality. People with dis abilities and their families claim that records about them that have been created by professionals, service delivery systems, and other state or private entities should be kept confidential. The claim is to control what others do with information that the individuals and families have disclosed (voluntarily or compulsorily). The essence of the claim is to be able to have access to correct, expunge, and consent to, or prevent, the publication (dissemination) of information that relates to those protected zones of privacy.

Privacy and confidentiality interact with a person's ability to act and live independently. If the core concept of autonomy is to have substance, if "I am my record" is a true statement, and if records are used to secure individualized and appropriate services (and accompanying cooperation and collaboration), then privacy and confidentiality enhance autonomy.

In addition, there is also a therapeutic basis for these claims. If individuals and their families are unable (because of fears that their privacy and confidentiality will be breached) to disclose information that is relevant to their claims to effective services, the claim to individualized and appropriate service delivery is undermined.

Finally, the claims to privacy and confidentiality can come into conflict with the claim to protection from harm. 
Private conduct (e.g., that of an abusive parent) can subject a person: with a disability to harm, and when private conduct (abuse, neglect, or maltreatment) causes harm, it also impairs the autonomy interest of the abused person. The parent's "choice" to abuse impairs the child's "choice" (presumed or explicitly stated to not be harmed.

\section{Integration}

The issue is whether individuals with disabilities have a right to be in the community and to participate in its typical activities. People with disabilities are often still segregated by placement into facilities and programs that are separate from those, used by individuals without disabilities. Many times, these separate programs are removed from typical community life. The claim is to integration (in contrast to segregation), to inclusion (in contrast to exclusion), and to participation (in contrast to limitation)-to being with, of, and among people who do not have disabilities. It also can be a claim to liberty-the interest in being free from unwarranted physical confinement-because liberty advances integration: One cannot be integrated unless one experiences liberty.

The claim to integration often is a legal claim that redresses segregation and is grounded in the core concept of antidiscrimination. Similarly, integration implicates the legal doctrine of the least restrictive environment: The state must place a person in the environment that is least restrictive of the person's liberty if the state has a legitimate reason to restrict the person in the first place. The prohibition against segregation thus includes a mandate for integration into typical environments (as appropriate), utilizing generic or specialize services (as appropriate) that support participation in those natural environments. Currently, disability service systems often fail to meet the spirit of this requirement. As a Kansas state-level administrator pointed out, service systems continue "this creation of almost parallel life systems for people-in a sense, we continue to set people aside; we just set them aside in smaller groups, no longer in institutions ... [or] group homes, but they are still set aside. They are not part of a real, meaningful community."

The claim to integration (to community membership and participation) is, in the words of several of the researcher respondents, a claim to the communal norm. There are two elements to this claim. First, people with disabilities and their families have a negative claim-that is, to be free from unjustified deprivation of liberty and unwarranted segregation (as, for example, by placement in institutions). Integration calls for deinstitutionalization. Second, persons with disabilities and their families assert a positive claim to be part of a community's typical activities, to participate in them, and to have access to those facilities and programs that individuals without disabilities use. This is an affirmative claim (expressed through home- and community-based services); it is a claim to be a member of and to participate in the generic, typical, normal activities of the community according to the choice of the individual or family. This claim is more elusive, explained one parent, because "As powerful as ADA is in creating a community free of discrimination, it cannot (indeed, no policy can) legislate a welcoming community." A state-level administrator in North Carolina concurred: "To secure inclusion, we have to move beyond a rights paradigm.... The new paradigm has to be a sense of togetherness."

Inclusion, a scholar respondent observed, is integration's philosophical and programmatic sister, implementing the claim to integration through various professional practices. These practices grow out of the philosophy of normalization. Inclusion refers to the placement or participation of a person with a disability or their family in generic services and environments, blending naturally occurring and specialized service supports in typical work, school, home, and leisure settings. Just as the physical environment is to be inclusive and least restrictive, so the methods of inclusion are to be the least drastic to meet the person's needs and most typical of the setting. Thus, "least restriction" and "least drastic" are expressions of the concepts of liberty, autonomy, and integration.

\section{Productivity and Contribution}

The issue is whether individuals with disabilities and their families will have the opportunity to lead lives that produce and contribute value to themselves and to their communities. The claim is to have the opportunities, with accommodations, to be productive and contributory.

This concept refers to engagement in income-producing work or in other unpaid work that contributes to a household or community. A common synonym for productivity is economic self-sufficiency. In this economic sense, productivity advances the work ethic that permeates our culture. For persons with disabilities, as for many who do not have disabilities, productivity means to have a job, to be able to earn part or all of one's living, and to be economically self-reliant and independent (in whole or in part). The claim is to the rights, entitlements, and services that allow people to have meaningful, productive lives. Productive people contribute to the economic health of the nation while avoiding the stigma of being a recipient of government largesse (being "on the dole" or a "welfare" client). Current services at times fail to promote productivity through supportive services, as explained by a regional provider-administrator in North Carolina:

We have created a "dependency model" in which we (providers) reat people with disabilities and their families as dependent, not contributing to [or] producing for society. There is a general disdain of the welfare system, and that carries over into disability policies, which have been attached to the welfare system. 
Clearly, promoting practices that support productivity and contribution rather than increasing dependency on services remains difficult for service providers to achieve.

Contribution, on the other hand, is a concept that denotes the psychological value of contributing to the wellbeing of one's self, one's family and friends, or one's community. The contributions of a person with a disability can allow other family members to work or be participants in the community; it has a ripple effect.

Moreover, in the concept of contribution we recognize that persons with disabilities, especially those who may not make money, nonetheless contribute to the moral, ethical, spiritual, and social fabric of their families and their communities. Contribution reflects the social dynamic of persons living together. A federal policy leader described this connection by saying, "The beauty of disability policy is that it can create a [sense of] community, satisfying the psychic needs we all have and contributing to changing the culture of our society."

Both productivity and contribution depend on access to services and thus relate to the core concept of antidiscrimination. Individualized and appropriate services further advance productivity and contribution as well. Special education (including access to the general curriculum), supported employment, independent living, assistive technology, and other services give people with disabilities the opportunity to be productive and contributory for themselves, their families, and their communities.

\section{Family Integrity and Unity}

The issue is whether policy and practice advance or impede the integrity and unity of the family. The claim is to have state support that makes it possible for the family to raise a child with a disability and for the child to have the benefits of being raised in, and living with, a family for as long as the family and child choose to or can remain as a single unit.

"We should try to help the family stay intact;" stated one official of a national group. "We don't ask [ourselves] what policies and practices make the family fragment." Family integrity and unity refers to preserving and strengthening the family as the core unit of society. It is reflected in services that maintain the family intact; respond to all family members; and take into account the family's cultural, ethnic, linguistic, or other socioeconomic traits and choices.

This concept recognizes that the family is the most fundamental unit of society and that it is usually beneficial to the child with a disability to live and grow within a family. This core concept reflects a strongly held value, according to a Kansas state administrator, "that every child is entitled to live in a family? if it is not the natural family, then it is a foster, extended, or adoptive family." Typically, families want to remain intact rather than to surrender legal or physical custody of their children in order to receive services for the children or themselves. "At one time, the choice was between sending a child to a state hospital or keeping the child at home," stated a Kansas advocate. Policies that can strengthen the family as the core unit of society and ensure that the services respond to all family members are based on family systems theory: The family's well-being affects an individual with a disability, and whatever happens to the individual affects the family. "[S]ervices to the family," said a Kansas administrator, "were developed to help the family keep the child in the home."

\section{Family Centeredness: Services to the Whole Family}

The issue is whether policy and practice encourage services to be provided to the entire family. The claim is to services that respond to the needs of the entire family of a person with a disability in an individualized and appropriate manner. Thus, the core concept of family-centered services relates to two other core concepts?cultural responsiveness and individualized and appropriate services. However, this concept stands on its own because, it emphasizes that services to the entire family advance the family's interests even as they also advance the interests of the member with a disability. Those services or programs (a) support families to raise their children with disabilities in the family home, (b) strengthen the role of the family as the primary caregiver, (c) maintain the family's intactness and unity, and (d) reunite families with their children who have been placed out of the family home. Social changes affect the nature of family-centered services, as a Kansas administrator noted:

Real cultural things affect policy... Not only do you have the effort at the policy level to use institutions less, to be more person-centered, but you also have the rise in single-parent families, both parents working, less natural community and family supports for families to rely on, and more severely involved children staying at home.

Thus, family-centered services are responsive to the family, however it is structured, and they respond to the family's needs, which may be exacerbated by social conditions.

\section{Cultural Responsiveness}

Some families, especially those from cultural, linguistic, and ethnically diverse backgrounds (as judged by demographic standards of this country and as defined by federal and state agencies), those from various socioeconomic strata, and those who identify with other cultural traits (e.g., same-gender partnerships or disability culture) may have different values, beliefs, perspectives, expectations, interpersonal styles, language, or attitudes than some policies may assume or than some service providers may hold. The claim is to services or supports that are provided in a manner that responds to the family's needs in culturally sensitive ways and thereby increases the likelihood of benefit to the family, person, or both. 
Accordingly, this claim recognizes the traditional value of pluralism, the changing demographics of the country, the desirability of ensuring family integrity/unity and familycentered services, and the potential for services to be more effective if they respond to a family's or person's culture.

\section{Accountability}

The issue is whether the policies and services indeed achieve the outcomes that they seek. The claim is to those techniques that hold policymakers and policy implementers accountable to those who are affected by their actions.

Accountability includes the following:

- procedural safeguards (legal accountability via procedural due process);

- direct or proxy representation by attorneys or others at the individual and system level, and recovery of actual or punitive damages and attorney fees;

- fiscal incentives and dis incentives built into services;

- independent peer or other professional standardsetting and monitoring (e.g., accreditation);

- internal and nonindependent professional evaluations or oversight (e.g., ombudsperson or human rights committees);

- recipient and consumer evaluations;

- legislative and budgetary oversight processes;

- financial management and reporting;

- independent fact-finding panels or entities (e.g., inspector general review);

- management techniques (e.g., service linkages, service coordination, "care/case" management); and

- capacity-building and program improvement activities (e.g., personnel development, research, technical assistance, model development, information and training, and similar activities).

The core concept of participatory decision-making also advances accountability at the system and individual level.

In addition, private-sector entities and federal, state, regional, and local agencies have a responsibility to be accountable to each other for activities that directly or indirectly affect the other. Accountability also includes a reflective, social, interpersonal dimension. Policymakers and service providers assert that individuals with disabilities and their families have a responsibility to be accountable to themselves, the public, and providers for their own behavior and for their use of public supports and resources. Accountability thus involves the individual, the family, policymakers, professionals, and various governments and private-sector entities. It is inherently a concept of reciprocity.

\section{Professional and System Capacity-Building}

Professional and system capacity-building?more accurately, building the capacity of individual professionals and of the systems in which they work? is a core concept for a very simple reason: When statutes and cases create rights and entitlements, they create laws "on the books." They do not, however, create laws "on the streets." That is to say, statutes and cases create claims to certain kinds of services, but they do not themselves ensure that the services will be delivered. All the legislative and judicial branches can do is to proclaim what the law is. To deliver on the proclamation is the job of the executive branch of government?the job of educators, physicians, psychologists, social workers, and others and of the adminis trators of the systems in which those professionals work. Indeed, few, if any, of the other core concepts will have any real meaning in the lives of families and individuals with disabilities unless professionals and systems have the capacity to satisfy families' and individuals' rights and entitlements.

\section{Prevention and Amelioration}

Given that some disabilities, or the effects of some disabilities, can be prevented or reduced, the issue is how for the benefit of society as a whole (social utilitarianism) and for individuals (individual utilitarianism) to prevent or reduce the effects of disabilities. The claim is to policies and practices that seek primary, secondary, and tertiary prevention of disability (see individualized and appropriate services).

Accordingly, some statutes have early intervention components and programs to address those who have, or are "at risk" of having, a disability. Prevention and amelioration is also stimulated by more inclusive and integrated programs: As more people with disabilities live within communities, community awareness of the importance of prevention may grow.

This research was supported by a grant from the National Institute on Disability and Rehabilitation Research to the Beach Center on Disability, Grant \#H133B980050. 